\title{
Sporotrichosis in Children: Case series and Narrative Review
}

\author{
Flavio Queiroz-Telles ${ }^{1}$ (D) Alexandro Bonifaz ${ }^{2} \cdot$ Regielly Cognialli $^{3,4} \cdot$ Bruno P. R. Lustosa $^{5} \cdot$ Vania Aparecida Vicente $^{5}$. \\ Hassiel Aurelio Ramírez-Marín ${ }^{6}$
}

Accepted: 18 January 2022 / Published online: 8 March 2022

(c) The Author(s), under exclusive licence to Springer Science+Business Media, LLC, part of Springer Nature 2022

\begin{abstract}
Purpose of Review Pediatric sporotrichosis has not been sufficiently studied; this review aims to evaluate the risk and prognostic factors related to the development of sporotrichosis associated to this age group. Also, we want to evaluate the causes of the increased number of cases of sporotrichosis in the pediatric population such as environmental changes in endemic areas, the biodiversity, and virulence among the pathogenic clade causing sporotrichosis in different areas of the globe, and especially the progression of the zoonotic transmission of infections caused by Sporothrix brasiliensis infections, associated to zoonotic transmission in Brazil and other endemic sporotrichosis countries.

Recent Findings After evaluating a case series of 40 patients, we found that pediatric sporotrichosis in Mexico is mainly caused by Sporothrix schenckii which prevails in rural areas and is mainly sapronotically transmitted. In Brazil, the longest and largest pediatric sporotrichosis outbreak is caused by Sporothrix brasiliensis, etiologically related to sick cats, directly from lesions containing a high yeast cell burden. When affecting children S. schenckii and S. brasiliensis may cause distinct clinical manifestations especially in the onset of the disease and affected anatomical site. In Mexico, most of the patients are successfully treated with potassium iodide, whereas in Brazil, all patients respond to itraconazole.

Summary Sporothrix schenckii is the major etiologic agent in Mexico, being sapronotically transmitted, while in Brazil, Sporothrix brasiliensis is only transmitted by cats. In Mexico, the disease prevails in male patients (60\%) from rural areas; in Brazil, the disease is more frequent in females $(60 \%)$ from an urban region. Due to the zoonotic sporotrichosis outbreak in Brazil, the time of evolution seems to be shorter in Brazilian patients than in Mexican patients. Most Brazilian patients presented with facial lesions, including ocular involvement, while in Mexico, most of the children presented upper limbs involvement. In Mexico, treatment with potassium iodide in children was observed to induce faster remission than itraconazole, but controlled studies are lacking to evaluate this versus itraconazole, due to the low number of cases. A comparative study should be designed to evaluate the best and safest antifungal therapy for pediatric sporotrichosis.
\end{abstract}

Keywords Child $\cdot$ Sporotrichosis $\cdot$ Subcutaneous mycosis $\cdot$ Implantation mycosis $\cdot$ Endemic diseases $\cdot$ Sporothrix schenckii $\cdot$ Sporothrix brasiliensis $\cdot$ Fungi $\cdot$ Humans

This article is part of the Topical Collection on Pediatric Fungal Infections

Flavio Queiroz-Telles

queiroz.telles@uol.com.br

1 Department of Public Health, Hospital de Clínicas, Federal University of Paraná, Curitiba, Brazil

2 Mycology Department, Hospital General de México "Dr. Eduardo Liceaga", Mexico City, México

3 Mycology Unit, Hospital de Clínicas, Federal University of Paraná, Curitiba, Brazil

4 Postgraduate Program in Internal Medicine and Health Science, Federal University of Paraná, Curitiba, Brazil

5 Basic Pathology Department, Microbiology, Parasitology and Pathology (PPGMPP) and Bioprocess Engineering and Biotechnology (PPGEBB) Graduate Programs, Federal University of Paraná, Curitiba, Brazil

6 Department of Dermatology, Weill Cornell Medical College, New York, NY, USA 


\section{Introduction}

Sporotrichosis is the most globally prevalent among the implantation or subcutaneous fungal infections $[1,2]$. This disease was first described In Baltimore, USA, by Benjamin R. Schenck in 1898, and is a subacute to chronic fungal infection caused by thermally dimorphic fungal species which are classified in the genus Sporothrix spp., englobing 66 species and comprising environmental and pathogenic species [3-9]. Sporotrichosis can be transmitted to humans by plant fragments and organic substrates (sapronotic), but also though traumatic injuries related to several animals types, including cats, dogs, squirrels, insects, and fishes (zoonotic). Some species of genus Sporothrix can be transmitted by both modes; sapronotic and zoonotic and are denominated saprozoonotic $[6,10]$. Sporothrix brasiliensis is unique because of its exclusive zoonotic transmission, causing an epizootic outbreak in expansion in some South American countries [10].

Members of the Sporothrix genus have a wide nature distribution, and they have been isolated from several environmental sources such as soil, water, decaying wood fragments like wood, leaves, thorns, sphagnum moss, hay bales, fruit pulp, and rosebush, among others [6, 7]. Environmentally, the Sporothrix spp. grows as a filamentous mold, but in tissue, it forms small budding yeast cells [11]. Phylogenetic, phenotypic, and physiologic differences have been identified among strains previously referred to as Sporothrix schenckii complex; therefore, isolates now are reported as Sporothrix genus members [6, 12, 13]. Within the Sporothrix genus, S. brasiliensis, S. schenckii, S. globosa, and S. luriei constitute the "clinical or pathogenic" clade whereas S. mexicana, S. humicola, S. pallida, S. chilensis, and S. stenoceras are considered in the "environmental clade" and rarely causing mammal infections. They have little epidemiological relevance for medicine or veterinary diseases [6]. The conidiogenous phenotypical aspects of the pathogenic or environmental species are mostly indistinguishable; thus, molecular methods like calmodulin gene sequences are the most informative for species identification [14]. Although some studies have suggested varied in vitro susceptibility to the antifungals used in sporotrichosis, no correlation has been demonstrated with clinical response to the antifungal therapy in human sporotrichosis $[15,16]$.

The estimative annual incidence of sporotrichosis around the globe is nearly 40,000 new cases per year, most of them occurring in hyperendemic areas like China, Mexico, Peru, and Brazil [1]. Most of the Sporothrix infections are observed in adults of both genders, but the number of children presenting these implantation mycoses has been increasing during the last decade. Pediatric sporotrichosis has received insufficient attention; risk and prognostic factors in this age group are unknown [17-19]. Pediatric cases are reported to be one-third of the total of sporotrichosis cases, and in hyper-endemic areas, pediatric sporotrichosis can account for half of all sporotrichosis cases $[18,19]$. A study found that $62 \%$ of sporotrichosis cases were reported in children under the age of 14 [20]. Therefore, this review aimed to update the worldwide epidemiology of sporotrichosis with focus on the progressive increase of cases in the pediatric population, and the outbreak expansion of cat-transmitted sporotrichosis in Brazil and in South American bordering countries.

\section{Methodology}

An extensive literature search was performed using PubMed, Cochrane, LILACS, SCOPUS, Springer Link, Web of Science, OviD, and Google Scholar databases. Articles in English, Spanish, German, and Chinese languages published from January 2016 through May 15, 2021, were considered. We included randomized clinical trials (RCTs), meta-analyses, systematic reviews, national guidelines, observational studies, book chapters, and case reports. The following terms were searched: ((("sporotrichosis in children") OR ("sporotrichosis in infants")) OR ("sporotrichosis in neonates")) OR ("pediatric sporotrichosis"). We also manually searched the references of selected articles. Selected articles were mutually agreed upon by the authors. Emphasis was given to a selection of case series since sporotrichosis in children is considered a rare disease with an increasing incidence. We analyzed the articles whose title or abstract described sporotrichosis in children or neonates (Fig. 1).

Special focus was given to epidemiological studies where $>50 \%$ of patients were children: We found new geographic areas of interest in Guerrero and Jalisco, México; Abancay, Peru; Rio de Janeiro, Brazil; Jilin, China; Madagascar; and Australia. Also, special attention needs to be given to ocular sporotrichosis in children, since we found several studies that state that this age group is at risk for this disease presentation.

We compared two recent series of pediatric sporotrichosis patients from Mexico and Brazil, in terms of clinical, epidemiological, microbiological, and therapeutic responses. The two series of cases were compared and statistically evaluated using the $T$-student test for independent variables.

The molecular identification, phylogenetic analysis, epidemiology, clinical, diagnosis, and treatment of 40 pediatric sporotrichosis from Mexico and Brazil were analyzed.

DNA extraction and purification of clinical pediatric Sporothrix isolated from Brazil were performed as previously described by Vicente et al. [21]. The calmodulin (CAL) locus region was selected to be amplified directly from the genomic 
Fig. 1 Search strategy for a narrative review of sporotrichosis in pediatric patients

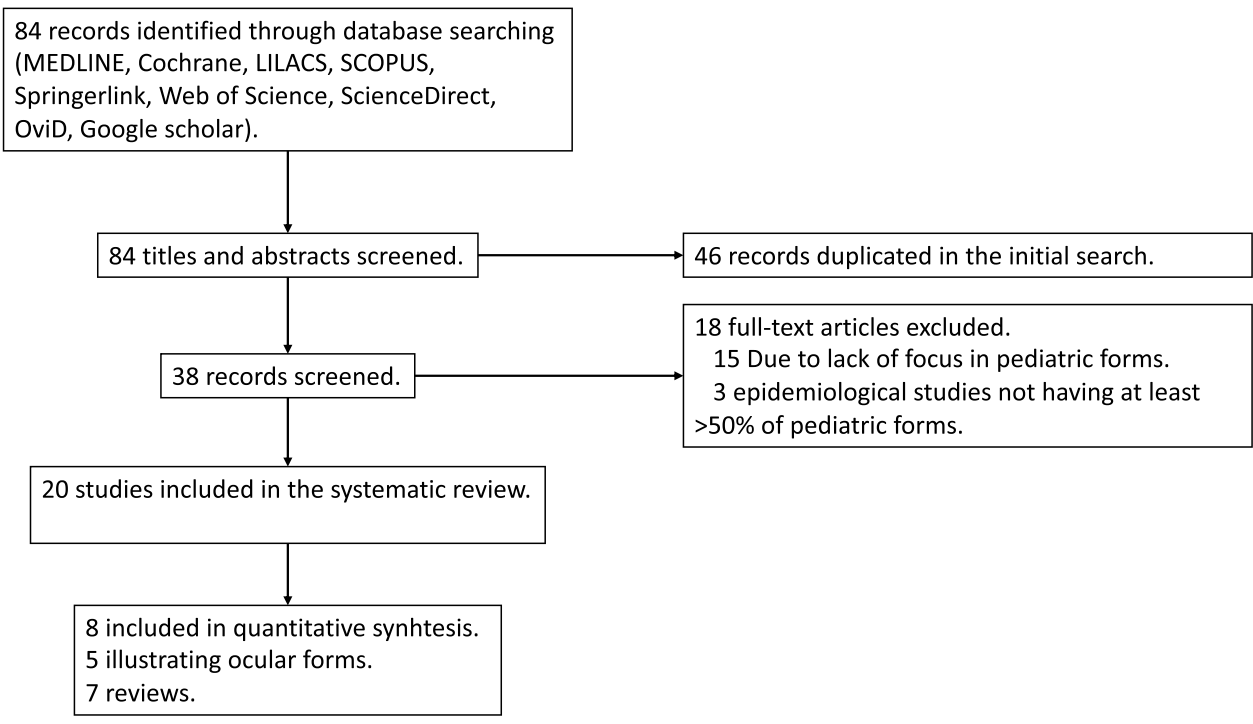

DNA by PCR using degenerate primers CL1 (5'-GAR TWC AAG GAG GCC TTC TC-3') and CL2A (5'-TTT TTG CAT CAT GAG TTG GAC-3'). The phylogenetic tree and bioinformatic analysis of obtained sequences were performed according to Rodrigues et al. [22] by using calmodulin sequences from reference strains (Table S1) selected from NCBI (National Center for Biotechnology Information) databank. The alignment of the CAL sequences was done with the online MAFFT interface [23]. Phylogenetic tree was constructed with 1000 bootstrap replicates using maximum likelihood method implemented in MEGA v7 software using Tamura 3-parameter as the best evolutionary model [24]. For Mexico isolates, the fungal DNA was extracted and purified using specific primers based on CAL gene sequences of clinically relevant members of the Sporothrix genus. PCR amplicons were resolved with $1.2 \%$ agarose gel electrophoresis [22].

\section{Ethics Statement}

The authors confirm that the ethical policies of the journal, as noted on the journal's author guidelines page, have been adhered to and the appropriate ethical review committee approval has been received. This study was approved by the Research Ethics Committee of Hospital de Clínicas Federal University of Paraná, Brazil, under the number CAAE-0024.0.009.000-10.

\section{Results}

\section{Eco-Epidemiologic Aspects of Sporotrichosis}

Sporotrichosis is found all over the world, but it is most common in warm, temperate, or tropical climates with temperatures ranging from 16 to $22^{\circ} \mathrm{C}$ [11]. This neglected endemic disease is a common implantation mycosis in South American countries that causes chronic disease in people of all ages [12]. The disease is most prevalent in South American countries, particularly Colombia, Peru, Brazil, Mexico, and Venezuela; however, it is also present in Asia and Africa, particularly Japan, India, and China. Sporadic cases have been reported in North America and Australia have also been documented [25]. Currently, the longest and largest zoonotic sporotrichosis outbreak of sporotrichosis is due to $S$. brasiliensis, affecting thousands of cats and humans and hundreds of dogs in Brazil. The transmission occurs directly by the yeast-like form and not only by traumatic inoculation, such as bites and scratches but via direct contact with infected secretions from feline cutaneous and mucosal lesions with non-disruptive cutaneous or mucosal barriers [26]. The possibility of transmission through infected respiratory secretions during a feline cough or sneezing episode has been investigated, and preliminary results have demonstrated that $S$. brasiliensis can be isolated from a cough and/ or sneezing episode from sick cats, directly in agar plates (Author personal communication). Cat transmitted sporotrichosis (CTS) has been widely documented in several Brazilian geographic regions, and it has recently expanded into neighboring countries in South America [6, 10, 27, 28]. Imported cases have been documented in Paraguay and the USA [10].

The incidence of sporotrichosis has changed due to radical changes in the lifestyles of the population of endemic regions, particularly in the pediatric population [19]. In comparison to the fixed variant, the lymphocutaneous type is the most common clinical form of sporotrichosis in pediatric patients (proportion 2:1) [19]. The disease's incidence has recently increased in children aged $5-9$, while it has decreased in younger children [17]. The majority of sporotrichosis cases reported in children aged 
10-14 years old primarily affect the face, which is likely due to increased susceptibility in an area exposed to a variety of traumatisms [17, 29, 30].

Increased skin trauma (e.g., living in homes with dirt floors) and contact with cats are risk factors for sporotrichosis among Peruvian children [11].

S. globosa is thought to be the etiological agent in 99.3\% of human sporotrichosis cases in Asia, particularly China $[31,32]$. S. schenckii is the dominant species in other endemic areas, including Australia and South Africa (94\%), as well as North America and parts of South America (89\%) [31]. S. brasiliensis (88\%) is the primary etiological agent of human and animal sporotrichosis in southeastern South America [21, 33].

In a retrospective study made at an endemic region in Jalisco, Mexico, by Mayorga et al. (2019) [34], 1134 cases of sporotrichosis confirmed with a positive culture from 1960 to 2017 were studied; the most frequently affected age group was $<1$ year- 15 years of age with $25.75 \%$ of the total of cases, findings consistent with those by RamirezSoto et al. (2011) [35] and (2015) [18] and Oyarce et al. (2016) [36]. In this retrospective study, it was also found the case with the youngest patient, a newborn of 2 days of age, bitten in the face by a mouse, reported by Valle-Meza and Barba-Rubio [37].

In another study by Estrada-Castañón et al. (2018) [19] made at Guerrero, Mexico, where 73 cases of cutaneous sporotrichosis were reported, $50 \%$ of the cases were found in children $<15$ years old, implying that they are constantly in contact with the causative agent while performing field activities, consistent with other developing countries with comparable statistics, both in traditions and population [19].

A retrospective study by Yao et al. (2020) [38 • in Jilin Province of China with 704 pediatric cases showed significantly more cases occur in younger children (63\% of cases 0-6 years old) than in older ones, $93 \%$ had lesions in the facial region, and $86 \%$ patients had the fixed cutaneous form. In Abancay city, located in a Peruvian South Central highland zone, 240 sporotrichosis pediatric cases were reported between 2004 and 2001. The mean age was 6 years old with a mean incidence rate of 81.4 cases per 100,00 individuals a year [20].

Children's sapronotic sporotrichosis has been linked to traumatic inoculation with contaminated material (plant debris). In Jilin China, S. schenckii infection was associated with cornstalk, used to make a fire in the rural areas [38•, 39]. The zoonotic transmission of sporotrichosis in adults and children is commonly described after cat traumatic and non-traumatic domestic feline interactions and also after squirrels' scratches and rat bites. Sporadic cases of Sporothrix spp. Infections were also reported after trauma caused by horses, birds, fishes, snakes, etc. [40-42]. Zoonotic epidemics caused by $S$. schenckii were reported in armadillo hunters, from Uruguay, and fishermen in Guatemala [43, 44].

In Brazil, there are two major disease transmission routes for humans: the sapronotic route, which involves direct contact with the soil and decomposing organic matter, and the zoonotic route, which involves felines actively participating in disease transmission. Zoonotic transmission by S. brasiliensis is much more common than sapronotic transmission, affecting the adult and pediatric populations. The epidemiological profile of CTS in Brazil is primarily characterized by children, the elderly, and women, as these groups have direct and frequent contact with these animals $[45,46]$.

The epizoonotic CTS outbreak caused by $S$. brasiliensis emerged in the state of Rio de Janeiro, Brazil, and continues in expansion, with proven reported cases in 25 states and reaching neighboring countries,like Argentina and Paraguay, and probable cases in Bolivia and Panama [47-52]. The progressive increase in the number of pediatric sporotrichosis could be explained by the spread of the CTS outbreak in Brazil and neighboring South American countries [20, 21]. In addition, during the SARS-COVID 2 outbreak in Brazil, in the last 2 years, many families incorporated pets (cats and dogs) into their houses to lessen anxiety among confined children. This new epidemiological scenario may be associated with the increase of CTS in Brazil in the last 24 months (author personal communication).

\section{Microbiologic and Molecular Aspects of Casual Agents of Sporotrichosis}

Sporothrix schenckii has a worldwide distribution being more prevalent in the tropical and in temperate climates [50]. S. globosa is characterized by the production of both hyaline and sessile brown to dark brown conidia presenting as terminal and lateral spherical conidia with growth inhibition above $35^{\circ} \mathrm{C}$, which can be associated to its lower virulence and its prevalence in the most superficial, fixed cutaneous type of infection [32]. The zoonotic and enzootic transmission of $S$. globosa is extremely rare. The species has been extensively reported in Asian countries such as India, Japan, and China, with some cases reported in Europe and the Americas [14, 51]. Moreover, the environmental niches of S. globosa and mode of transmission are still unclear [32].

S. brasiliensis is considered an emerging fungal pathogen characterized as zoonotic associated to cat to human transmission and/or enzootic transmission (cat-to-cat/cat-to dog) through bites, scratches, or contact with exudate from the cutaneous lesions of sick cats with epidemic and/or epizootic potential $[22,48 \bullet \bullet]$. It is a geophilic thermally dimorphic fungus that exhibits a saprophytic mycelium phase at room temperature $\left(25-28{ }^{\circ} \mathrm{C}\right)$ and a cigar-shaped yeast pathogenic phase at $36-37^{\circ} \mathrm{C}$ [52]. According to the level 
of pigmentation in the media culture, the species present two different phenotypes that differ in the in vitro antifungal drugs susceptibility which have been described in domestic felines in the hyperendemic area of Brazil and Argentina $[10,53,54]$.

Likewise, in animal models, $S$. brasiliensis is more virulent than $S$. schenckii, and it is the only thermo-dimorphic fungus transmitted directly in the yeast phase [10].

The $S$. luriei is a less common fungal species related to a mild human sporotrichosis infection in South Africa and to a dog isolate in south of Brazil $[15,55]$; however, as this strain does not produce melanin, it has a lower virulent profile [56].

Molecular data has shown that several Sporothrix spp. isolated from the environment have a wide nature distribution, as they are present on several environmental sources such as soil, decaying plants fragments like wood, leaves, thorns, sphagnum moss, hay bales, fruit pulp, and rosebush, insects, among other sources [13]. Thus, these strains are allocated on the "environmental clade" (Fig. 2).

\section{Clinical Presentation}

In contrast to adult sporotrichosis, which affects any anatomic site, pediatric sporotrichosis most commonly affects the face and limbs, particularly the hands and fingers [57, 58]. In $25 \%$ of cases, infection is limited to the initial site of inoculation; as is common in facial lesions, children are more likely than adults to contract these "fixed" infections $[39,59]$. Pediatric patients usually develop a cutaneous disease of the face or limbs, either "lymphocutaneous" with multiple nodular lesions spreading proximally along the lymphatic vessels or "fixed" with a single chronic ulcerative lesion $[20,60]$. The average duration of the disease varies depending on the region, the agent, the patient's age, and immune status. The disease can last for 1 to 2 months on average [20], which could be explained by the difficulty of children expressing symptoms and parental care [17-20].

Osteoarticular disease is uncommon; it is caused by direct inoculation or hematogenous spread [17]. Pulmonary infection, disseminated disease, and meningitis are extremely rare, occurring mostly in patients with compromised cellular immunity [17-20].

Children generally have more prolonged and frequent contact with animals and, therefore, are commonly infected [61]. Nonetheless, they have a higher immunological resistance which causes the previously described limited lesions, such as the fixed form, as well as slightly elevated serological titers [62].

Due to facial contact with animals, this age group is also predisposed to ocular mucosal lesions, causing conjunctivitis, uveitis, choroiditis, episcleritis, and retrobulbar lesions $[63,64]$. Dacryocystitis can occur when the lacrimal duct is obstructed [65, 66]. Retrobulbar lesions, such as chorioretinitis, are more commonly associated with hematogenous spread. It is not uncommon for the ocular mucosa and regional lymph nodes to be affected at the same time, which causes the Parinaud syndrome [67].

In a review by Ramirez-Soto (2015) [58], it was found that cases of sporotrichosis in the ocular adnexa (eyelids, lacrimal gland, and brows) have been linked to children under the age of 15 . One explanation proposed for these findings is that children have more opportunities to play in crop fields and come into contact with cats, making them more likely to be exposed to the fungus [58]. Another possibility is that, even after the same level of exposure, children are more vulnerable to more severe forms of disease than adults [58].

Sporotrichosis in ocular adnexa seems to be restricted to Peruvian and Brazilian populations [54, 64-67].

Another study in Jilin, China, by Zhang et al. (2015) [68] where local farmers burn wood splinters and cornstalks for heating and cooking, and where more than 2000 cases of sporotrichosis are diagnosed each year, causing the disease's prevalence to skyrocket, it was discovered that 43 of the 72 patients diagnosed with eyelid sporotrichosis were children, with the youngest patient being 2 months old [68]. The peak incidence occurred from December to May, with the highest incidence occurring in April [68]. Forty three percent of the patients had a clear history of trauma. Furthermore, 13 of these patients had a history of cornstalk-related eyelid trauma, six had reed-related trauma, and three had woodrelated trauma [68].

\section{Assessment and Diagnosis}

From a mycologic point of view, the gold standard for the diagnosis of sporotrichosis is the isolation of Sporothrix spp. from clinical samples. On the other hand, the isolation of Sporothrix spp. is a slow-growing organism, and samples can be contaminated. Direct mycologic and histopathologic examinations can also be used but in immunocompetent patients, both have a low sensibility (20-30\%). In addition, the microscopic visualization of yeast cells by both methods is usually non-specific [69]. Histopathological analysis may have some additional findings like "asteroid bodies", but their finding is also infrequent, and they may be not pathognomonic, for this disease [70]. Although the immunodiagnosis tests based on ELISA and Western blot methods are validated, they are not commercially available [25, 62]. A latex hemagglutination text is commercialized, but its sensibility depends on the clinical form of the disease [71]. Intradermal tests using sporotrichin skin test antigen may be helpful; however, it is not a commercially available standardized [19, 39]. Molecular methods like DNA detection by PCR have been 


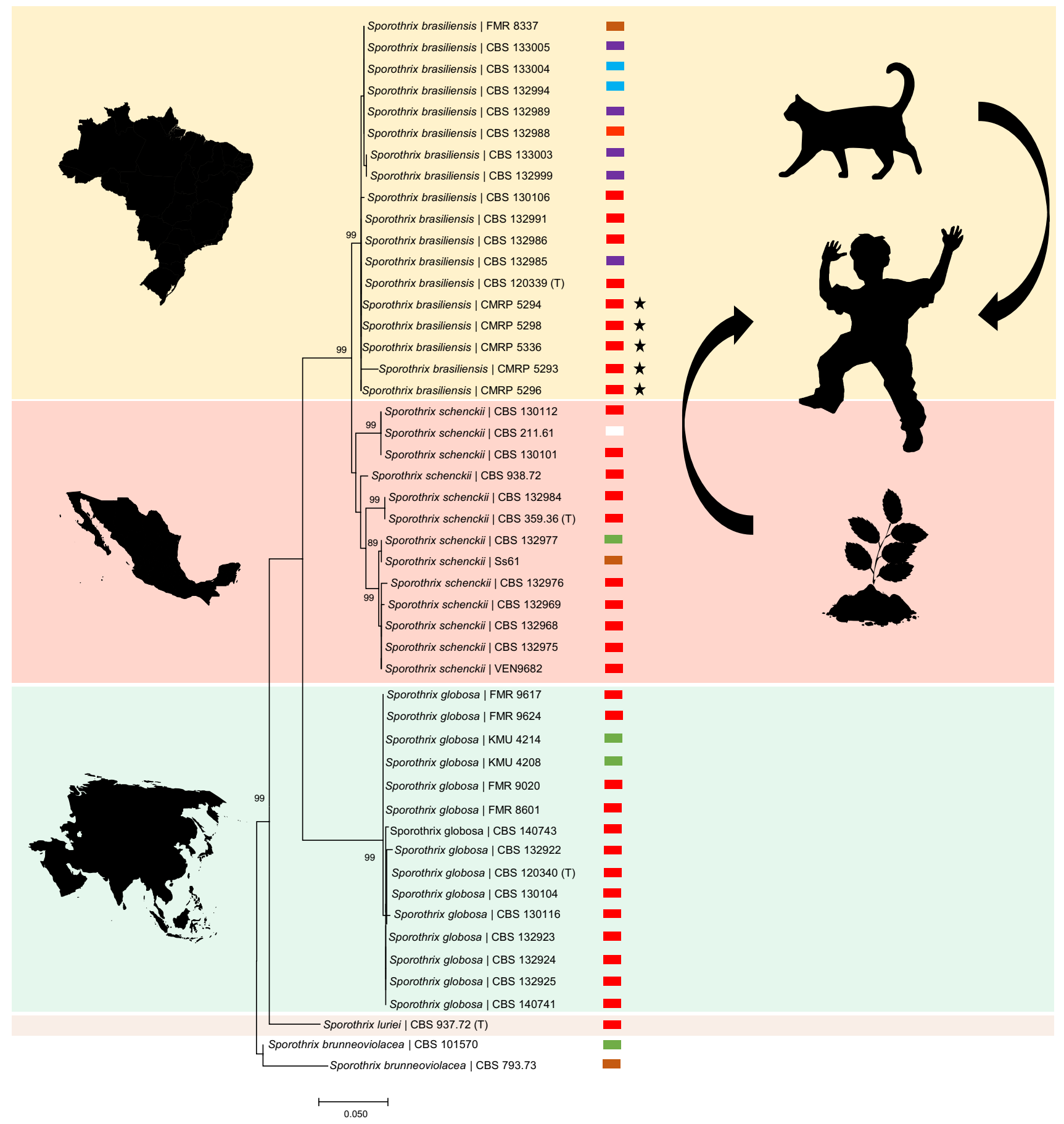

Sporothrix pediatric route of infection:

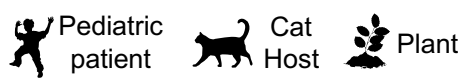

\section{Sources:}

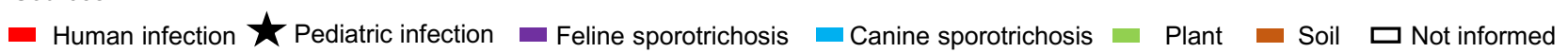

Fig. 2 Phylogenetic tree of the Sporothrix pathogenic clade based on calmodulin near-complete, genes constructed with maximum likelihood implemented in MEGA 7.0.26. Bootstrap values $>80$ from 1000 resampled data sets are shown. Sporothrix brunneviolacea (CBS
793.73) was taken as outgroup. Pathogenic species are highlighted in color: red Sprototrix schenckii strictu sensu; ochre Sporothrix brasiliensis, green Sporothrix globosa, gray Sprothrix luriei. The colored squares represent the source of the isolation 
also developed to overcome the limitations of histopathologic and direct exams. The DNA detection revealed a specificity of $95 \%$ and sensibility ranging from 83 to $92 \%$ [33]. But like most immunological tests, they are not useful for most patients around the globe because they are not commercially available [72•].

In Brazil, because of the rapid increase of CTS, the Ministry of Health (MOH) made a recent recommendation with new evidence diagnostic levels to detect early human sporotrichosis, due to the issues related to mycologic, serologic, and immunologic diagnosis of sporotrichosis during the zoonotic outbreak. According to the Brazilian MOH diagnostic criteria, proved CTS is defined when the patients present clinical manifestations contact with sick cats, microbiological and histopathological evidence of sporotrichosis. Probable CTS was considered when the patients present clinical signs associated to contact with sick cats who had a microbiologic diagnosis of sporotrichosis made by a veterinarian and/or a veterinarian laboratory. This practical approach leads to early detection of the cases and reduction of the disease morbidity and the time duration of therapy [73] (Table 1).

\section{Differential Diagnosis}

Sporotrichosis may be clinically similar to many other infectious and non-infectious diseases, both tegumentary and systemic [25]. The most common are cutaneous nocardiosis, non-tuberculous mycobacteriosis, leishmaniasis, piodermitis, cat-scratch disease, chromoblastomycosis, syphilis, pyoderma gangrenosum, osteomyelitis, rosacea, granuloma annulare, and rheumatoid arthritis [25]. Tuberculosis is a frequent differential diagnosis in the sporotrichosis endemic areas. Pulmonary infection by Sporothrix spp may mimic nodular and cavitary tuberculotic lesions as well as the central nervous involvement may be misdiagnosed as chronic meningeal tuberculosis [25].

\section{Treatment}

For children with cutaneous or lymphocutaneous sporotrichosis, oral itraconazole (in doses of 6 to $10 \mathrm{mg} / \mathrm{kg} / \mathrm{day}$, with a maximum dose of $400 \mathrm{mg} /$ day) is recommended, though lower doses (100 mg/day) have also been effective [26, 74-76]. Nevertheless, it is important to emphasize that alkaline drinks and foods, like milk and lactic derivatives, may reduce itraconazole gastrointestinal absorption, due to the raising of the acid gastric $\mathrm{pH}$ [75]. In countries where itraconazole oral solution is not available, in infants during the lactation period or for children that cannot swallow the itraconazole capsules, one therapeutic option is to administrate itraconazole diluted in citric juice.

After the lesions have healed, therapy should be continued for another 2 to 4 weeks. Most patients require therapy for 3 to 6 months, and it is successful in more than $90 \%$ of cases $[74,76]$. Fluconazole is less effective and should be used as a last resort for children who are unable to tolerate other therapies or who do not absorb itraconazole [74]. Saturated solution of potassium iodide (SSKI) is the least costly option for lymphocutaneous infection and can be administered to children, although it has been linked with many side effects, and sometimes can be poorly tolerated by children, side effects which include a strong metallic taste, salivary gland swelling, rash, gastrointestinal intolerance, and fever [77]. In children, a dose of $50 \mathrm{mg}$, or 1 drop 3 times daily in water or juice, is given at first, and then increased by 1 drop per dose per day as tolerated (maximum of $1 \mathrm{drop} / \mathrm{kg}$ or 40 to 50 drops 3 times daily, whichever is lower) [74]. In some countries, potassium iodide (Mexico and Venezuela) is the treatment of choice in children, due to the low cost and affordability [20, 25, 78, 79]. Nowadays in In Brazil, itraconazole is freely offered by the Brazilian MOH. Even at low doses in children, potassium iodide has an excellent

Table 1 Evidence level for the diagnosis of zoonotic transmission of human Sporotrichosis in Brazil

\begin{tabular}{|c|c|c|c|}
\hline Evidence level & Epidemiology & Clinicals & Laboratory \\
\hline Possible & History of trauma or contact with sick cats & Suggestive lesions & Absent \\
\hline Probable & History of trauma or contact with sick cats & Suggestive lesions & $\begin{array}{l}\text { Veterinarian diagnosis } \\
\text { A Microbiologic proved diagnosis by the veterinarian or } \\
\text { veterinarian laboratory } \\
\text { B Regional detection of feline cases from other sources: } \\
\text { Zoonosis Control Centers, Mobile contacts to a reference } \\
\text { center, etc.... }\end{array}$ \\
\hline Proved & History of trauma or contact with sick cats & Suggestive lesions & Positive culture \\
\hline Discarded & History of trauma or contact with sick cats & Suggestive lesions & $\begin{array}{l}\text { Negative culture and/or lack of microbiologic or histopatho- } \\
\text { logic diagnosis of sporotrichosis }\end{array}$ \\
\hline
\end{tabular}

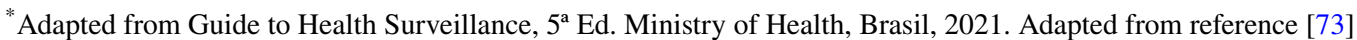


safety and efficacy profile; however, the frequent adverse events limit its widespread use [79]. Extracutaneous disease should be treated with amphotericin B as soon as possible $[25,78]$.

\section{Prevention}

Sporotrichosis can be avoided by wearing protective clothing and by limiting animal exposures in high-risk environments [24].

The outbreaks from the classic transmission route, in which $S$. schenckii and S. globosa prevail, require the removal of fungus sources in nature [45]. Examples of such measures include neutering street animals and treating sick cats, and education about responsible animal ownership and knowledge of the main aspects of Sporothrix transmission, particularly in hyperendemic areas. Infected animals that die or euthanatized must be incinerated rather than buried, preventing Sporothrix from spreading in the soil and the pathogen from progressing in nature [24].

\section{Cases Series of Pediatric Sporotrichosis in Mexico and Brazil}

To compare the clinical, epidemiological, microbiological, and therapeutic responses observed in pediatric sporotrichosis, we compared two recent series of patients from Mexico and Brazil (Table 2).

In Mexico, a recent national survey managed to capture 20 children with sporotrichosis, all of them from the southcentral region (States of Guerrero, Hidalgo, Puebla, and Mexico City), with an average age of 10.4 years old (range 4-17 years old), $60 \%$ of them male, most of them (75\%) with no occupational exposure, despite this, the rest had a positive history of rural activities, including agriculture and children working as carpenter's helper (5\%) and floriculturist (5\%), $60 \%$ of them reported a history of trauma either at school or with vegetation, 2 of them revealed a history of a squirrel scratch, and 2 of them a positive history of contact with corn leaves. Sixty five percent presented the lymphocutaneous form of the disease. The mean time of the clinical manifestations onset was 127.5 days (30-240 days). The clinical topography of the disease was always in exposed areas, especially arms (60\%); $95 \%$ of children got a proved $S$. schenckii implantation mycosis; only 1 child had affection by proved S. globosa. In $90 \%$ of children, the mycologic exam was negative. Sixty percent received therapy with potassium iodide; from these patients, only 1 failed to achieve a complete mycological cure. Thirty five percent received itraconazole; from these patients, 2 (10\%) failed to achieve mycological cure. The mean duration of treatment to achieve mycological cure $(85 \%)$ or a significant improvement of the disease (15\%) was 3.4 months; the mean duration of treatment with itraconazole showed to be higher (4.4 months) than the duration of treatment with KSSI (3.2 months). Two patients were treated with thermotherapy (Fig. 3).

In Brazil, a survey conducted at the Hospital de Clínicas of the Federal University of Paraná, located in Curitiba, Brazilian Southern Region. Between 2005 and July 2021, 175 patients were diagnosed with sporotrichosis. Among these, 171 (98.3\%), were reported as zoonotic transmission $4(1.7 \%)$ via the sapronotic route. Molecular identification was performed in 24 isolates and $91.7 \%$ of these samples $(n=22)$; Sporothrix brasiliensis was the etiological agent identified. Most of the sporotrichosis cases were diagnosed between 2019 and $2021(n=105,60 \%)$. The incidence rate increased from 0.27 cases $/ 100.000$ patients in 2011 to 30.4 cases/100.000 patients until July 2021. The prevalence rate was 4.97 cases per 100,000 patients. Among all 175 patients, 21 were pediatric patients, and almost half $(47.6 \%)$ of them were diagnosed during the last 2 years, especially during the COVID-19 lock down measures, in Curitiba. The pediatric patients have an average age of 9.9 years old (range 1-17 years old), 60\% of them female, all of them had contact with sick cats. The mean time of the disease onset was 38.5 days (07-120) and 50\% of the patients presented the lymphocutaneous form of the disease, $30 \%$ cutaneous fixed and $20 \%$ ocular forms, some of them with Parinaud syndrome. The face was the anatomical site more affected (50\%). Diagnosis evidence level was made according to the Brazilian MOH criteria (Table 1). Most of the patients presented "probable sporotrichosis" $(65 \%)$, while in $35 \%$, the diagnosis was microbiologically proved, with identification of $S$. brasiliensis as the etiological agent. All patients were treated with itraconazole at the daily dose of 06 to $10 \mathrm{mg} / \mathrm{kg}$ or 100 to $200 \mathrm{mg}$ per day, for older children, during 3.3 months in average. Most of the patients (95\%) were cured and in one is improving and therapy is ongoing (Fig. 4).

\section{Discussion}

We compared two geographically distinct pediatric populations with proved and probable sporotrichosis. Sporothrix schenckii is the main etiologic agent in Mexico, being sapronotically transmitted, while in Brazil, Sporothrix brasiliensis is only transmitted by cats. The two groups do not differ in terms of age (mean age of 10.4 versus 9.9 years old, $p=0.718$ ). In Mexico, the disease prevails in male patients $(60 \%)$ versus female (40\%), from rural areas. In opposition, in Brazil, the disease is more frequent in females $(60 \%)$ than in male pediatric patients (40\%), both from an urban region. All Brazilian cases are from Curitiba and/or cities from the Great Curitiba. All infections were acquired after 


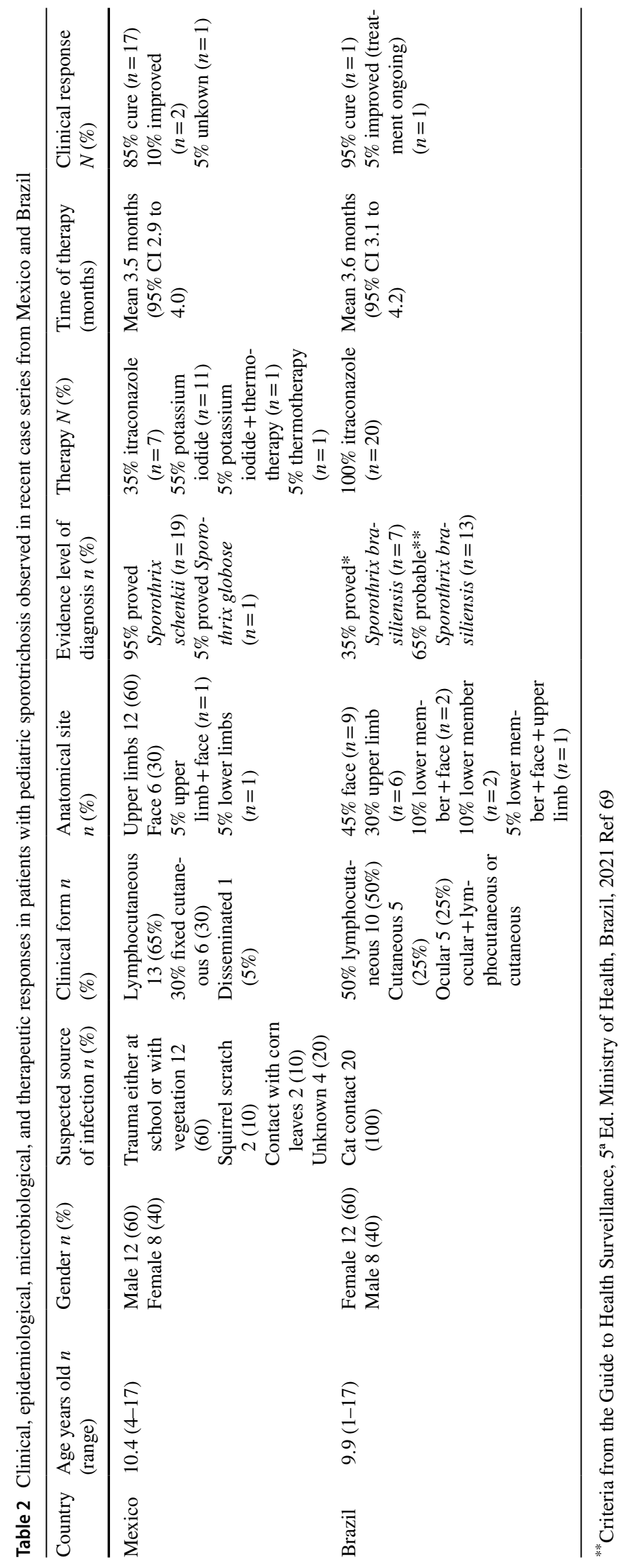


Fig. 3 Clinical and laboratorial aspects of pediatric sporotrichosis in Mexico. Fixed cutaneous sporotrichosis (A), lymphangitic cutaneous sporotrichosis and positive intradermal reaction to sporothricin (B). Facial sporotrichosis $(\mathrm{C})$. Asteroid body (Wright, 40×) (E). Culture of Sporotrix schenckii on Sabouraud media. Filamentous phase of S. schenckii (Erythrocin, $40 \times)(\mathrm{F})$

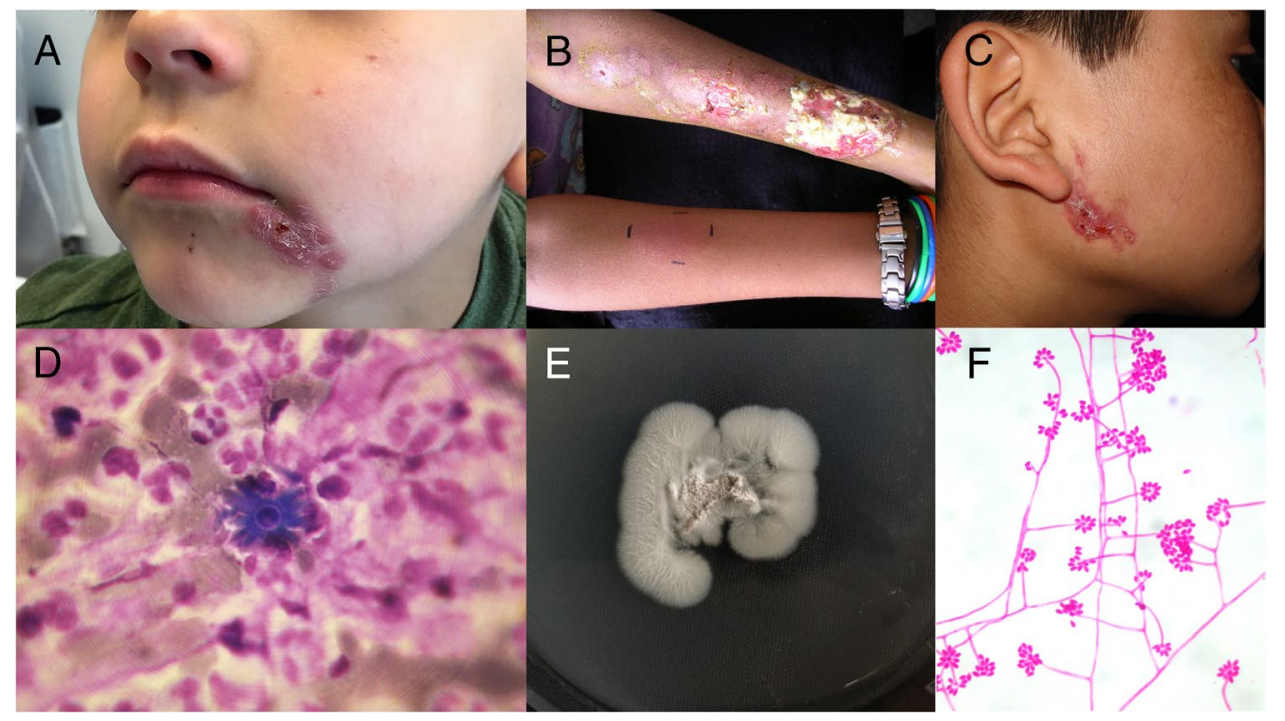

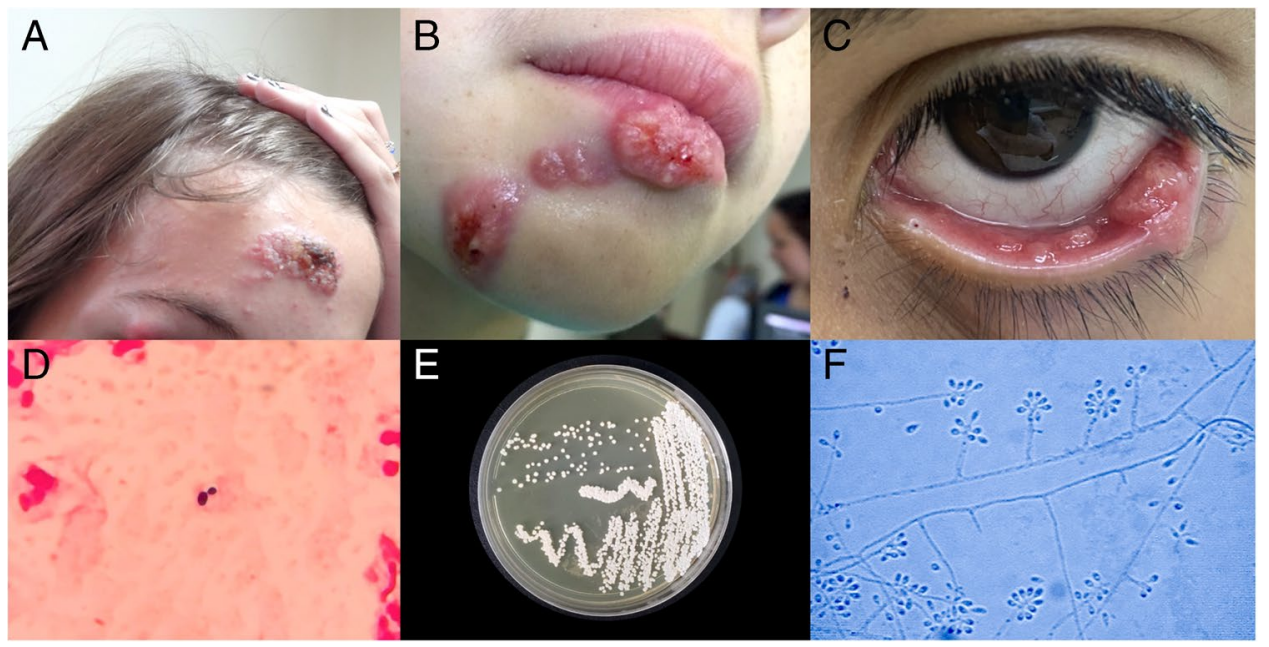

Fig. 4 Clinical and laboratorial aspects of pediatric cat transmitted sporotrichosis in Brazil. Facial lesions in a teenage patient (A). Lip and mentonian lesion in a child, after kissing a cat (B). Granulomatous tarsal conjunctivitis transmitted by cat purulent secretion (C). Direct examination from skin lesion exudate from a patient showing a single yeast budding cell in Gram staining, $\times 1000$ (D). E Mycelial phase yielding of Sporothrix brasiliensis after conjunctival swabbing from a patient with ocular sporotrichosis. Sabouraud dextrose agar at $28{ }^{\circ} \mathrm{C}$ after 5 days (E). Direct examination from skin lesion exudate of cat with sporotrichosis due to Sporothrix brasiliensis, showing a high burden of yeast like cells in Giemsa staining $(1000 \times)$ feline contact, including bites, scratches, and especially the simple contact with feline ulcerated lesions' exudates or secretions. Due to the zoonotic sporotrichosis outbreak in Brazil, the time of evolution seems to be shorter in Brazilian patients than in Mexican patients. When comparing the two groups of patients with a $T$-student test for independent variables, there is a significant difference in the time of onset of the disease. The mean time of onset in Mexican cases is 127.5 days, compared with 38.5 days, in Brazilian patients. Figure 5. Most of the Brazilian patients presented with facial lesions, including ocular involvement, while in Mexico, most of the children presented upper limbs involvement. These findings are related to $S$. brasiliensis virulence factors, like the melanization of its cell wall, transmission directly in the yeast phase, feline lesions with high fungal burden, and frequent children cat physical interactions. Most of the cases in Brazil were diagnosed using the $\mathrm{MOH}$ diagnosis criteria, i.e., probable or proved S. brasiliensis infection, leading to faster diagnosis, and the reduction of morbidity and time of therapy.

In Mexico, treatment with $\mathrm{KI}$ in children was observed to induce faster remission than itraconazole, but controlled studies are lacking to evaluate this versus itraconazole, due to the low number of cases. It should be noted that KI 


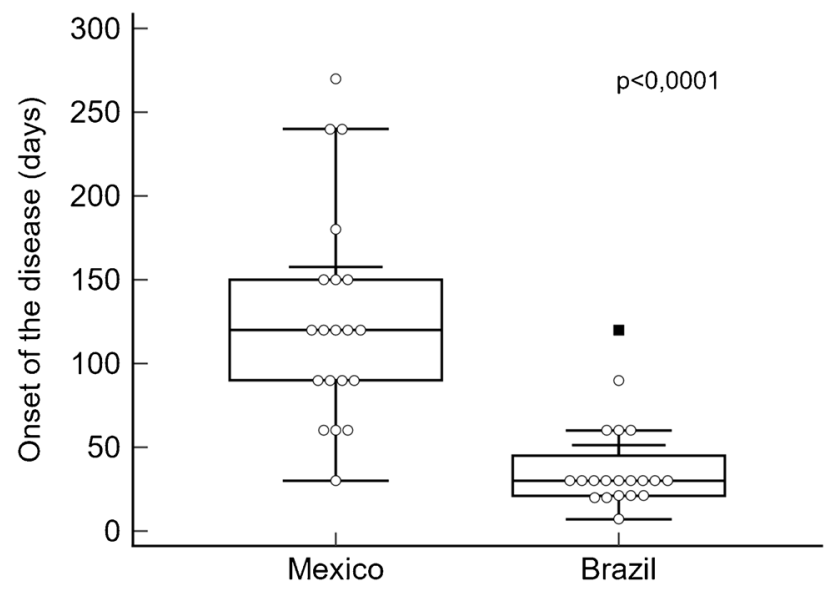

Fig. 5 Boxplot of the time of evolution in days of pediatric sporotrichosis cases from Mexico and Brazil (t-Test for independent samples $p<0,0001)$

mechanism of action is not well understood; it is known that works as an immunostimulant. In general, we know that the immune response of children is more robust than in adults and the elderly, so a possible explanation is that when children receive treatment with potassium iodide, a greater immune response begins and therefore a shorter response time than that found in adult patients. In the other hand, in Brazil, itraconazole is offered to patients for free, by the Brazilian $\mathrm{MOH}$. Although there is evidence in the literature showing the advantages of itraconazole over KSSI, most of the published data are from adult patients $[72 \bullet, 74,80]$. A comparative study should be designed to evaluate the best and safest antifungal therapy for pediatric sporotrichosis.

\section{Conclusions}

Sporothrix schenckii is the main etiologic agent in Mexico, being sapronotically transmitted, while in Brazil, Sporothrix brasiliensis is only transmitted by cats. In Mexico, the disease prevails in male patients $(60 \%)$ from rural areas; in Brazil, the disease is more frequent in females (60\%) from an urban region. Due to the zoonotic sporotrichosis outbreak in Brazil, the time of evolution seems to be shorter in Brazilian patients than in Mexican patients. Most of the Brazilian patients present with facial lesions, including ocular involvement while in Mexico, most of the children presented upper limbs involvement.

In Mexico, treatment with SSKI in children was observed to induce faster remission than itraconazole, but controlled studies are lacking to evaluate this versus itraconazole, due to the low number of cases. A comparative study should be designed to evaluate the best and safest antifungal therapy for pediatric sporotrichosis.

Supplementary Information The online version contains supplementary material available at https://doi.org/10.1007/s12281-022-00429-x.

Acknowledgements All the photographs of patients with sporotrichosis are published with their approval. The patients in this manuscript have given written informed consent to publication of their case details. All authors revised the manuscript and provided critical feedbacks. All authors approved the final version of the manuscript for submission. All authors believe that the manuscript represent honest work.

Author contribution Dr. Queiroz-Telles: Conceptualization (lead); methodology (lead); review and editing (supporting). Dr. Bonifaz: Supervision (lead); validation (lead); review and editing (supporting). Msc Cognialli; mycologic diagnosis (supporting). MSc Lustosa, and M.S, PhD Vicente; molecular biology (supporting). Hassiel Dr Ramirez-Marin: Writing-review and editing (supporting); writing-original Draft Preparation (lead).

\section{Compliance with Ethical Standards}

Conflict of Interest The authors declare no competing interests.

Human and Animal Rights Informed Consent This article does not contain any studies with human or animal subjects performed by any of the authors.

\section{References}

Papers of particular interest, published recently, have been highlighted as:

- Of importance

$\bullet$ Of major importance

1. Bongomin F, Gago S, Oladele RO, Denning DW. Global and multi-national prevalence of fungal diseases-estimate precision. J Fungi (Basel). 2017;3(4):57. https://doi.org/10.3390/jof30 40057.

2. Queiroz-Telles F, Nucci M, Colombo AL, Tobón A, Restrepo A. Mycoses of implantation in Latin America: an overview of epidemiology, clinical manifestations, diagnosis and treatment. Med Mycol. 2011;49(3):225-36. https://doi.org/10.3109/13693 786.2010 .539631 .

3. Ngubane NP, Dreyer LL, Oberlander KC, Roets F. Two new Sporothrix species from Protea flower heads in South African Grassland and Savanna. Antonie Van Leeuwenhoek. 2018;111(6):965-79. https://doi.org/10.1007/ s10482-017-0995-3.

4. Wang H, Lun Y, Lu Q, Liu H, Decock C, Zhang X. Ophiostomatoid fungi associated with pines infected by Bursaphelen chusxylophilus and Monochamus alternatus in China, including three new species. MycoKeys. 2018;39:1. https://doi.org/ 10.3897/mycokeys.39.27014.

5. Sun JZ, Liu XZ, Jeewon R, Li YL, Lin CG, Tian Q, Zhao Q, Xiao XP, Hyde KD, Nilthong S. Fifteen fungicolous Ascomycetes on edible and medicinal mushrooms in China and Thailand. Asian J Mycol. 2019;2(1):129-69. https://doi.org/10.5943/ ajom/2/1/7. 
6. Rodrigues AM, Della Terra PP, Gremião ID, Pereira SA, Orofino-Costa R, de Camargo ZP. The threat of emerging and re-emerging pathogenic Sporothrix species. Mycopathologia. 2020;12:1-30. https://doi.org/10.1007/s11046-020-00425-0.

7. Musvuugwa T, de Beer ZW, Dreyer LL, Duong T, Marincowitz $\mathrm{S}$, Oberlander KC, Roets F. New ophiostomatoid fungi from wounds on storm-damaged trees in Afromontane forests of the Cape Floristic Region. Mycol Prog. 2020;19(1):81-95. https:// doi.org/10.1007/s11557-019-01545-8.

8. Ostafińska A, Jankowiak R, Bilański P, Solheim H, Wingfield MJ. Six new species of Sporothrix from hardwood trees in Poland. MycoKeys. 2021;82:1. https://doi.org/10.3897/mycok eys.82.66603.

9. Chang R, Zhang X, Si H, et al. Ophiostomatoid species associated with pine trees (Pinus spp.) infested by Cryphaluspiceae from eastern China, including five new species. MycoKeys. 2021;83:181-208. https://doi.org/10.3897/mycokeys.83. 70925.

10. Etchecopaz A, Toscanini MA, Gisbert A, Mas J, Scarpa M, Iovannitti CA, Bendezú K, Nusblat AD, Iachini R, Cuestas ML. Sporothrix brasiliensis: a review of an emerging South American fungal pathogen, its related disease, presentation and spread in Argentina. J Fungi. 2021;7(3):170. https://doi.org/10.3390/jof70 30170.

11. Patterson TF, Sutton DA. Sporothrix schenckii complex (Sporotrichosis). In: Principles and Practice of Pediatric Infectious Diseases. Elsevier Inc. 2018; pp 1253-1255.

12. Marimon R, Gene J, Cano J, Trilles L, Lazéra MS, Guarro J. Molecular phylogeny of Sporothrix schenckii. J Clin Microbiol. 2006;44:3251-6. https://doi.org/10.1128/JCM.00081-06.

13. de Beer ZW, Duong TA, Wingfield MJ. The divorce of Sporothrix and Ophiostoma: solution to a problematic relationship. Stud Mycol. 2016;83:165-91. https://doi.org/10.1016/j.simyco. 2016.07.001.

14. Marimon R, Cano J, Gene J, Sutton DA, Kawasaki M, Guarro J. Sporothrix brasiliensis, S. globosa, and S. mexicana: three new Sporothrix species of clinical interest. J Clin Microbiol 2007;45:3198-3206. https://doi.org/10.1128/JCM.00808-07

15. Marimon R, Serena C, Gene J, Cano J, Guarro J. In vitro antifungal susceptibilities of five species of Sporothrix. Antimicrob Agents Chemother. 2008;52:732-4. https://doi.org/10.1128/ AAC.01012-07.

16. Queiroz-Telles F, Fahal AH, Falci DR, Caceres DH, Chiller T, Pasqualotto AC. Neglected endemic mycoses. Lancet Infect Dis. 2017;17(11):e367-77.

17. Lyon GM, Zurita S, Casquero J, Holgado W, Guevara J, Brandt ME, Douglas S, Shutt K, Warnock DW, Hajjeh RA. Sporotrichosis in Peru Investigation Team. Population based surveillance and a case-control study of risk factors for endemic lymphocutaneous sporotrichosis in Peru. Clin Infect Dis. 2003; 36(1):34-39. https://doi.org/10.1086/345437

18. Ramírez-Soto MC. Sporotrichosis: the story of an endemic region in Peru over 28 years (1985 to 2012). PLoS ONE. 2015;10: e0127924. https://doi.org/10.1371/journal.pone.01279 24.

19. Estrada-Castañón R, Chávez-López G, Estrada-Chávez G, Bonifaz A. Report of 73 cases of cutaneous sporotrichosis in Mexico. An Bras Dermatol. 2018;93(6):907-9. https://doi.org/10.1590/ abd1806-4841.20187726.

20. Ramírez-Soto MC. Sporotrichosis among children of a hyperendemic area in Peru: an 8-year retrospective study. Int J Dermatol. 2017;56:868-72. https://doi.org/10.1111/ijd.13643.

21. Vicente VA, Attili-Angelis D, Pie MR, Queiroz-Telles F, Cruz LM, Najafzadeh MJ, De Hoog GS, Zhao J, Pizzirani-Kleiner A. Environmental isolation of black yeast-like fungi involved in human infection. Stud Mycol. 2013;75:391-406. https://doi. org/10.3114/sim.2008.61.14.

22. Rodrigues AM, de Melo TM, de Hoog GS, Schubach TM, Pereira SA, Fernandes GF, et al. Phylogenetic analysis reveals a high prevalence of Sporothrix brasiliensis in feline sporotrichosis outbreaks. PLoS Negl Trop Dis. 2013;7: e2281. https://doi. org/10.1371/journal.pntd.0002281.

23. Katoh K, Toh H. Recent developments in the MAFFT multiple sequence alignment program. Brief Bioinform. 2008;9:286-98.

24. Kumar S, Stecher G, Tamura K (2016) MEGA7: Molecular evolutionary genetics analysis version 7.0 for bigger datasets. Mol Biol Evol 22; https://doi.org/10.1093/molbev/msw054

25. Orofino-Costa R, Macedo PM, Rodrigues AM, Bernardes- Engemann AR. Sporotrichosis: an update on epidemiology, etiopathogenesis, laboratory and clinical therapeutics. An Bras Dermatol. 2017;92:606-20. https://doi.org/10.1590/abd1806-4841.20172 79.

26. de Lima Barros MB, Schubach AO, de Vasconcellos de Oliveira RVC, Martins EB, Teixeira JL. Treatment of cutaneous sporotrichosis with itraconazole: study of 645 patients. Clin Infect Dis. 2011; 52:e200-e206. https://doi.org/10.1093/cid/cir245

27. Barros MB, Schubach AO, do Valle AC, Galhardo MCG, Conceição- Silva F, Schubach TMP, Reis RS, Wanke B, Marzochi $\mathrm{KBF}$, Conceição MJ. Cat-transmited sporotrichosis epidemic in Rio de Janeiro, Brazil: description of a series of cases. Clin Infect Dis. 2004; 38:529-35. https://doi.org/10.1086/381200

28. Gremião ID, Miranda LH, Reis EG, Rodrigues AM, Pereira SA. Zoonotic epidemic of sporotrichosis: cat to human transmission. PLoS Pathog. 2017;13: e1006077. https://doi.org/10.1371/journ al.ppat.1006077.

29. Barraza LL, Tolomelli JB, Cunha CG, Bernardes Filho F, Towersey L, Hay R, Schechtman RC, Nery JAC. Facial cutaneous sporotrichosis in a boy. J EmergMed. 2019;56:222-3. https://doi. org/10.1016/j.jemermed.2018.10.031.

30. Barros MB, Costa DL, Schubach TM, do Valle AC, Lorenzi NP, Texeira JL, Schubach O. Endemic of zoonotic sporotrichosis: profile of cases in children. Pediatr Infect Dis J. 2008;27:246-50. https://doi.org/10.1097/INF.0b013e31815bf309.

31. Zhang Y, Hagen F, Stielow B, Rodrigues AM, Samerpitak K, Zhou X, Feng P, Yang L, Chen M, Deng S, Li S, Liao W, Li R, Li F, Meis JF, Guarro J, Teixeira M, Al-Zahrani HS, Camargo ZP, Zhang L, Hoog GS. Phylogeography and evolutionary patterns in Sporothrix spanning more than 14,000 human and animal case reports. Persoonia. 2015;35:1-20. https://doi.org/ 10.3767/003158515X687416.

32. Moussa TAA, Kadasa NMS, Al Zahrani HS, Ahmed SA, Feng P, van den Ende AHGG, Zhang Y, Kano R, Li F, Li S, Song Y, Dong B, Rossato L, Dolatabadi S, Hoog GS. Origin and distribution of Sporothrix globosa causing sapronoses in Asia. J Med Microbiol. 2017;66:560-9. https://doi.org/10.1099/jmm.0. 000451.

33. Rodrigues AM, de Hoog G, Zhang Y, de Camargo ZP. Emerging sporotrichosis is driven by clonal and recombinant Sporothrix species. Emerg Microbes Infect. 2014;3: e32. https://doi.org/10. 1038/emi.2014.33.

34. Mayorga-Rodríguez J, Mayorga-Garibaldi JL, Muñoz-Estrada VF, Ramírez RM. Esporotricosis: serie de 1,134 casos en una zona endémica de México. Med Cutan Iber Lat Am. 2019;47(1):24-8.

35. Ramírez-Soto MC, Andagua-Castro J, Lizárraga-Trujillo J, Aguilar-Ancori EG, Pezo-Ochoa JD. Esporotricosis en pacientes que acuden a un centro médico de referencia, en Abancay, Perú. Rev Perú Med Exp Salud Pública. 2011;28(3):508-12.

36. Oyarce JA, García C, Alave J, Bustamante B. Caracterización epidemiológica, clínica y de laboratorio de esporotricosis en pacientes de un hospital de tercer nivel en Lima-Perú, entre los 
años 1991 y 2014. Rev Chil Infectol. 2016;33(3):315-21. https:// doi.org/10.4067/S0716-10182016000300012.

37. Valle-Meza JA, Barba-Rubio J. Esporotricosis facial en un lactante. Mem I Cong Mex Derm. 1961: 273-275.

38. Yao L, Song Y, Cui Y, et al. Pediatric sporotrichosis in Jilin Province of China (2010-2016): a retrospective study of 704 Cases. J Pediatric Infect Dis Soc. 2020;9(3):342-8. https://doi. org/10.1093/jpids/piz052. The largest published pediatric sporotrichosis case series.

39. Bonifaz A, Saúl A, Paredes-Solis V, Fierro L, Rosales A, Palacios C, Araiza J. Sporotrichosis in childhood: clinical and therapeutic experience in 25 patients. Pediatr Dermatol. 2007; 24:369-72. https:// doi.org/https://doi.org/10.1111/j.1525-1470. 2007/00452.x

40. Kwon-Chung KJ, Bennett JE. Sporotrichosis. In: Kwon-Chung KJ, Bennett JE, editors. Medical mycology. Philadelphia: Lea \& Febiger; 1992. p. 707-29.

41. Saravanakumar PS, Eslami P, Zar FA. Lymphocutaneous sporotrichosis associated with a squirrel bite: case report and review. Clin Infect Dis. 1996;23:647-8. https://doi.org/10.1093/clinids/ 23.3.647.

42. Lacaz CS, Porto E, Martins JEC, Heins-Vaccari EM, Melo NT. Esporotricose e outras micoses gomosas. In: Lacaz CS, Porto E, Martins JEC, Heins-Vaccari EM, Melo NT editores. Tratado de micologia médica. São Paulo: Sarvier; 2002. p. 479-97.

43. Conti-Díaz IA. Sporotrichosis in Uruguay: epidemiologyc and clinical aspects. In: Pan American Health Organization Scientific Publication $\mathrm{n}^{\circ}$ 396. Washington DC: Pan American Health Organization; 1980. p. 312-321

44. Mayorga R, Cáceres A, Toriello C, Alvarez O, Mamirez AZ, Mariat F. An endemic area of sporotrichosis in Guatemala. Sabouraudia, 1978; 16:185-98)

45. Barros MB, Schubach AO, Schubach TM, Wanke B, LambertPassos SR. An epidemic of sporotrichosis in Rio de Janeiro, Brazil: epidemiological aspects of a series of cases. Epidemiol Infect. 2008;136:1192-6. https://doi.org/10.1017/S095026880 7009727.

46. Freitas DF, Valle AC, da Silva MB, Campos DP, Lyra MR, de Souza RV, Veloso VG, Zancopé-Oliveira RM, Bastos FI, Galhardo MCG. Sporotrichosis: an emerging neglected opportunistic infection in HIV-infected patients in Rio de Janeiro. Brazil PLoS Negl Trop Dis. 2014;8: e3110. https://doi.org/10.1371/ journal.pntd.0003110.

47. Marques SA, Franco SRVS, Camargo RMP, Dias LDF, HaddadJúnior V, Fabris VE. Esporotricose do gato doméstico (Felis catus): transmissão humana. Rev Inst Med Trop São Paulo. 1993;35:327-30. https://doi.org/10.1590/S0036-4665199300 0400004.

48.• Rossow JA, Queiroz-Telles F, Caceres DH, et al. A one health approach to combatting Sporothrix brasiliensis: narrative review of an emerging zoonotic fungal pathogen in South America. J Fungi. 2020;6(4):247. https://doi.org/10.3390/jof6. This paper brings to light, the importance of One Health actions to detect the progression of cat transmitted sporotrichosis in South America.

49. Etchercopaz A, Toscanini M, Gisberti A, et al. Sporothrix brasiliensis: a review of an emerging south american fungal pathogen, its related disease, presentation and spread in Argentina. J Fungi. 2021;7:170. https://doi.org/10.3390/jof7030170.

50. Azam NK, Selvarajah GT, Santhanam J, Abdul Razak MF, Ginsapu SJ, James JE, Suetrong S. Molecular epidemiology of Sporothrix schenckii isolates in Malaysia. Med Mycol. 2020;58(5):617-25. https://doi.org/10.1093/mmy/myz106.

51. Madrid H, Cano J, Gené J, Bonifaz A, Toriello C, Guarro J. Sporothrix globosa, a pathogenic fungus with widespread geographical distribution. Rev Iberoam Micol. 2009;26(3):218 22. https://doi.org/10.1016/j.riam.2009.02.005.

52. Barros MB, de Almeida PR, Schubach AO. Sporothrix schenckii and Sporotrichosis. Clin Microbiol Rev. 2011;24(4):633-54. https://doi.org/10.1128/CMR.00007-11.

53. Macêdo-Sales PA, Souza LO, Della-Terra PP, Lozoya-Pérez NE, Machado RL, da Rocha EM, Lopes-Bezerra LM, Guimarães AJ, Rodrigues AM, Mora-Montes HM, Dos Santos AL. Coinfection of domestic felines by distinct Sporothrix brasiliensis in the Brazilian sporotrichosis hyperendemic area. Fungal Genet Biol. 2020;140: 103397. https://doi.org/10.1016/j.fgb.2020.103397.

54. Oliveira MM, Almeida-Paes R, Corrêa-Moreira D, Borba CD, Menezes RC, Freitas DF, Do Valle AC, Schubach AD, Barros MB, Nosanchuk JD, Gutierrez-Galhardo MC. A case of sporotrichosis caused by different Sporothrix brasiliensis strains: mycological, molecular, and virulence analyses. Mem Inst Oswaldo Cruz. 2019;114: e190260. https://doi.org/10.1590/0074-02760 190260.

55. Oliveira DC, Lopes PG, Spader TB, Mahl CD, Tronco-Alves GR, Lara VM, Santurio JM, Alves SH. Antifungal susceptibilities of Sporothrix albicans, S. brasiliensis, and S. luriei of the $S$. schenckii complex identified in Brazil. J Clin Microbiol. 2011;49(8):3047-9. https://doi.org/10.1128/JCM.00255-11

56. Cruz IL, Figueiredo-Carvalho MH, Zancopé-Oliveira RM, Almeida-Paes R. Evaluation of melanin production by Sporothrix luriei. Mem Inst Oswaldo Cruz. 2018;113(1):68-70. https://doi.org/10.1128/JCM.00255-11.

57. Pappas PG, Tellez I, Deep AE, et al. Sporotrichosis in Peru: description of an area of hyperendemicity. Clin Infect Dis. 2000;30:65-70. https://doi.org/10.1086/313607.

58. Ramirez Soto MC. Sporotrichosis in the ocular adnexa: 21 cases in an endemic area in Peru and review of the literature. Am J Ophthalmol. 2016;162:173-9. https://doi.org/10.1016/j.ajo. 2015.11.015.

59. Rafal ES, Rasmussen JE. An unusual presentation of fixed cutaneous sporotrichosis: a case report and review of the literature. J Am Acad Dermatol. 1991;25:928-32. https://doi.org/10.1016/ 0190-9622(91)70286-B.

60. Camacho E, León-Navarro I, Rodríguez-Brito S, Mendoza M, Niño-Vega GA. Molecular epidemiology of human sporotrichosis in Venezuela reveals high frequency of Sporothrix globosa. BMC Infect Dis. 2015;15:94-10. https://doi.org/10.1186/ s12879-015-0839-6.

61. Orofino-Costa R, de Macedo PM, Bernardes-Engemann AR. Hyperendemia of sporotrichosis in the Brazilian Southeast: learning from clinics and therapeutics. Curr Fungal Infect Rep. 2015;9:220-8. https://doi.org/10.1007/s12281-015-0235-0.

62. Bernardes-Engemann AR, de Lima BM, Zeitune T, Russi DC, Orofino-Costa R, Lopes-Bezerra LM. Validation of a serodiagnostic test for sporotrichosis: a follow-up study of patients related to the Rio de Janeiro zoonotic outbreak. Med Mycol. 2015;53:28-33. https://doi.org/10.1093/mmy/myu058.

63. Kurosawa A, Pollock SC, Collins MP, Kraff CR, Tso MO. Sporothrix schenckii endophthalmitis in a patient with human immunodeficiency virus infection. Arch Ophthalmol. 1988;106:37680. https://doi.org/10.1001/archopht.1988.01060130402030.

64. Curi AL, Félix S, Azevedo KM, Estrela R, Villar EG, Saraça G. Retinal granuloma caused by Sporothrix schenckii. Am J Ophthalmol. 2003;136:205-7. https://doi.org/10.1016/S00029394(03)00083-7.

65. Freitas DF, Lima IA, Curi CL, Jordão L, Zancopé-Oliveira RM, Valle AC, Galhardo MCG, Curi ALL. Acute dacryocystitis: another clinical manifestation of sporotrichosis. Mem Inst Oswaldo Cruz. 2014;109:262-4. https://doi.org/10.1590/00740276130304 
66. de Macedo PM, Sztajnbok DC, Camargo ZP, Rodrigues AM, Lopes-Bezerra LM, Bernardes-Engemann AR, Orofino-Costa R. Dacryocystitis due to Sporothrix brasiliensis: a case report of a successful clinical and serological outcome with low dose potassium iodide treatment and oculoplastic surgery. 2015;172(4):1116-9. https://doi.org/10.1111/bjd.13378

67. Ferreira CP, Nery JA, de Almeida AC, Ferreira LC, Corte-Real S, Conceição-Silva F. Parinaud's oculoglandular syndrome associated with Sporothrix schenckii. IDCases. 2014;1:38-9. https:// doi.org/10.1016/j.idcr.2014.05.001.

68. Zhang Y, Wang Y, Cong L, Yang H, Cong X. Eyelid sporotrichosis: unique clinical findings in 72 patients. 2015;57(1):44-7. https://doi.org/10.1111/ajd.12286

69. Arenas R, Sánchez-Cardenas CD, Ramirez-Hobak L, Ruíz Arriaga LF, Vega Memije ME. Sporotrichosis: from KOH to molecular biology. J Fungi (Basel). 2018;4(2):62. https://doi. org/10.3390/jof4020062.

70. Rodríguez G, Sarmiento L. The asteroid bodies of sporotrichosis. Am J Dermatopathol. 1998;20(3):246-9. https://doi.org/10. 1097/00000372-199806000-00004.

71. Blumer SO, Kaufman L, Kaplan W, McLaughlin DW, Kraft DE. Comparative evaluation of five serological methods for the diagnosis of sporotrichosis. Appl Microbiol. 1973;26(1):4-8. https:// doi.org/10.1128/am.26.1.4-8.1973.

72. Thompson GR, 3rd, Le T, Chindamporn A, Kauffman CA, Alastruey-Izquierdo A, Ampel NM, et al. Global guideline for the diagnosis and management of the endemic mycoses: an initiative of the European Confederation of Medical Mycology in cooperation with the International Society for Human and Animal Mycology. Lancet Infect Dis. 2021;21(12):e364-e74. A recent global guideline for the management of the endemic mycoses, including sporotrichosis.

73. Guide to Health Surveillance, $5^{a}$ Ed. Ministry of Health, Brazil, 2021https://bvsms.saude.gov.br/bvs/publicacoes/guia_vigil ancia_saude_1ed_atual.pdf. Published 2021. Accessed November $18,2021$.
74. Kauffman CA, Bustamante B, Chapman SW, Pappas PG. Clinical practice guidelines for the management of sporotrichosis: 2007 update by the Infectious Diseases Society of America. Clin Infect Dis. 2007;45:1255-65. https://doi.org/10.1086/522765.

75. Fotaki N, Klein S. Mechanistic understanding of the effect of PPIs and acidic carbonated beverages on the oral absorption of itraconazole based on absorption modeling with appropriate in vitro data. Mol Pharm. 2013;10(11):4016-23. https://doi.org/ 10.1021/mp4003249.

76. Kauffman CA, Pappas PG, McKinsey DS, Greenfield RA, Perfect JR, Cloud GA, Thomas CJ, Dismukes WE. Treatment of lymphocutaneous and visceral sporotrichosis with fluconazole. Clin Infect Dis. 1996;22:46-50. https://doi.org/10.1093/clinids/ 22.1.46.

77. Kauffman CA. Endemic mycoses: blastomycosis, histoplasmosis, and sporotrichosis. Infect Dis Clin North Am. 2006;20:645-62. https://doi.org/10.1016/j.idc.2006.07.002.

78. Queiroz-Telles F, Bonifaz A, Rossow J, Chindamporn A. Sporothrix and sporotrichosis. Encyclopedia of Infection and Immunity. 2022. https://doi.org/10.1016/B978-0-12-818731-9. 00046-X

79. Macedo PM, Lopes-Bezerra LM, Bernardes-Engemann AR, Orofino-Costa R. New posology of potassium iodide for the treatment of cutaneous sporotrichosis: study of efficacy and safety in 102 patients. J Eur Acad Dermatol Venereol. 2015;29:719-24. https://doi.org/10.1111/jdv.12667.

80. Lima Barros MB, Schubach AO, de Vasconcellos Carvalhaes de Oliveira R, Martins EB, Teixeira JL, Wanke B. Treatment of cutaneous sporotrichosis with itraconazole-study of 645 patients. Clin Infect Dis. 2011;52(12):e200-6.

Publisher's Note Springer Nature remains neutral with regard to jurisdictional claims in published maps and institutional affiliations. 